\title{
Antrodia cinnamomea extract inhibits the proliferation of tamoxifen-resistant breast cancer cells through apoptosis and skp2/ microRNAs pathway
}

Yu-Shih Lin ${ }^{1,8+}{ }^{\text {, Yin-Yin Lin }}{ }^{2+}$, Yao-Hsu Yang ${ }^{2,3,11}$, Chun-Liang Lin ${ }^{4,5}$, Feng-Che Kuan ${ }^{6}$, Cheng-Nan Lu', Geng-He Chang ${ }^{10,11}$, Ming-Shao Tsai ${ }^{10}$, Cheng-Ming Hsu ${ }^{10}$, Reming-Albert Yeh ${ }^{10}$, Pei-Rung Yang ${ }^{2}$, I-Yun Lee ${ }^{2}$,

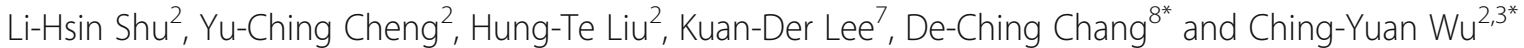

\begin{abstract}
Background: Breast cancer is the most common cancer in women and affects 1.38 million women worldwide per year. Antiestrogens such as tamoxifen, a selective estrogen receptor (ER) modulator, are widely used in clinics to treat ER-positive breast tumors. However, remissions of breast cancer are often followed by resistance to tamoxifen and disease relapse. Despite the increasing understanding of the resistance mechanisms, effective regimens for treating tamoxifen-resistant breast cancer are limited. Antrodia cinnamomea is a traditional medicinal mushroom native only to Taiwan. In this study, we aimed to examine in vitro effect of antrodia cinnamomea in the tamoxifenresistant cancer.

Methods: Antrodia cinnamomea was studied for its biological activity against proliferation of tamoxifen-resistant breast cancer by XTT assay. Next, the underlying mechanism was studied by flow cytometry, QPCR and Western's blotting assay.

Results: Our results revealed that the ethanol extract of antrodia cinnamomea (AC) can inhibit the growth of breast cancer cells, including MCF-7 cell and tamoxifen-resistant MCF-7 cell lines. Combination treatment with AC and $10^{-6} \mathrm{M}$ tamoxifen have the better inhibitory effect on the proliferation of tamoxifen-resistant MCF-7 cells than only AC did. AC can induce apoptosis in these breast cancer cells. Moreover, it can suppress the mRNA expression of skp2 (S-phase kinase-associated protein 2) by increasing the expressions of miR-21-5p, miR-26-5p, and miR-30-5p in MCF-7 and tamoxifen-resistant MCF-7 cells.
\end{abstract}

Conclusions: These results suggest that the ethanol extract of antrodia cinnamomea could be a novel anticancer agent in the armamentarium of tamoxifen-resistant breast cancer management. Moreover, we hope to identify additional pure compounds that could serve as promising anti-breast cancer candidates for further clinical trials.

Keywords: Breast cancer, Tamoxifen-resistant, skp2, microRNA, Antrodia cinnamomea

\footnotetext{
*Correspondence: biodcc@ccu.edu.tw; smbepigwu77@gmail.com

${ }^{\dagger}$ Equal contributors

${ }^{8}$ Institute of Molecular Biology, National Chung Cheng University, No.168,

Sec. 1, University Rd., Minhsiung Chiayi County 62102, Taiwan, Republic of

China

${ }^{2}$ Department of Chinese Medicine, Chiayi Chang Gung Memorial Hospital,

Chiayi, Taiwan

Full list of author information is available at the end of the article
}

(c) The Author(s). 2018 Open Access This article is distributed under the terms of the Creative Commons Attribution 4.0 International License (http://creativecommons.org/licenses/by/4.0/), which permits unrestricted use, distribution, and

reproduction in any medium, provided you give appropriate credit to the original author(s) and the source, provide a link to the Creative Commons license, and indicate if changes were made. The Creative Commons Public Domain Dedication waiver (http://creativecommons.org/publicdomain/zero/1.0/) applies to the data made available in this article, unless otherwise stated. 


\section{Background}

Breast cancer is the most common cancer in women and affects 1.38 million women worldwide per year [1]. In the past 20 years, the development of new therapeutics has significantly reduced mortality rates. Antiestrogens such as tamoxifen, a selective estrogen receptor modulator, are widely used in clinics to treat estrogen receptor (ER)-positive breast tumors. An adjuvant therapy study of tamoxifen demonstrated a 40 to $50 \%$ reduction in the odds of recurrence and reduced mortality and temporary remissions in 30 to $50 \%$ of patients with metastatic disease [2]. However, remissions of breast cancer are often followed by resistance and disease relapse [3]. Previous studies have reported several mechanisms associated with resistance to tamoxifen, including altered expression of microRNA [3, 4]. Despite the increasing understanding of the resistance mechanisms, effective regimens for treating tamoxifen-resistant breast cancer are limited. Therefore, developing treatment regimens for tamoxifen-resistant breast cancer that are more effective and accompanied by minimal adverse effects remains a priority in breast cancer research.

Antrodia cinnamomea $(\mathrm{AC})$ is a medical mushroom native only to Taiwan and is originally found growing in the empty rotting trunk of Cinnamomum kanehirai Hay. AC has been reported to have antiinflammatory, hepatoprotective, antitumor, antioxidant, and immunomodulatory properties [5-11]. In the past years, several compounds, including steroid acids, triterpenoids, and polysaccharides, have been isolated from $\mathrm{AC}[10,12-18]$. Some studies have reported that the extract of AC can inhibit the growth of breast cancer cell lines [19, 20]. Moreover, antrodin $\mathrm{C}$, extracted from $\mathrm{AC}$ can inhibit epithelial-tomesenchymal transition and the metastasis of breast cancer cells [21]. However, the effects of AC on acquired tamoxifen-resistant breast cancer and the underlying mechanism remain unclear. In this study, we investigated the effects of the fruiting body extract of AC on tamoxifen-resistant breast cancer and identified the underlying mechanism.

\section{Methods}

\section{Cell culture and treatment}

MCF-7 cells (human breast cancer cell line) were obtained from the American Type Culture Collection. The MCF-7 cells were cultured in Eagle's Minimum Essential Medium (EMEM) (Invitrogen Corp., Carlsbad, CA), supplemented with $10 \% \mathrm{FBS}$ at $37{ }^{\circ} \mathrm{C}$ and $5 \% \mathrm{CO} 2$. For the acquired tamoxifen resistant breast cancer cells, MCF-7 cells were cultured in Eagle's Minimum Essential Medium containing 10\% charcoal-stripped fetal bovine serum with $1 \mu \mathrm{M}$ tamoxifen over a period of 3 months and then maintaining them in $10^{-7} \mathrm{M}$ tamoxifen for more than 9 months. Powdered fruiting bodies of 10 months cultivated dried Antrodia cinnamomea (250 g, brought form Fong Chun biotecology Co., Taiwan) were soaked in $500 \mathrm{ml}$ ethanol for three days. The sample was filtered with filter paper while the residue was further extracted twice more under the same conditions. The filtrates collected from three separate extractions were combined and evaporated to dryness under vacuum (27 g). The extract was dissolved in ethanol and stored at $-20{ }^{\circ} \mathrm{C}$. For all experiments, final concentrations of the tested compound were prepared by diluting the stock with ethanol. Antcin K, antcin $\mathrm{C}$, antcin B, methyl antcinate B, eburicoic acid and dehydroeburicoic acid were kindly gifts from Dr. Lih-Geeng Chen. Human breast cancer cells were cultured to $60-70 \%$ confluence prior to treatment. Medium was then replaced with fresh medium containing $\mathrm{AC}$ in DMSO (dimethyl sulfoxide) at the indicated concentrations. Cells treated with DMSO alone were used as untreated controls. The parental cells without treatment were used as blank control.

\section{XTT assay}

The indicated breast cancer cell lines were plated at a density of $10^{3}$ per well, in 96-well plates, in EMEM containing $10 \%$ FBS and 1\% penicillin/streptomycin. Once attached, the medium was replaced with EMEM containing $10 \%$ FBS and $1 \%$ penicillin/streptomycin. The cells were then treated with indicated drugs for 24 or $48 \mathrm{~h}$; and absorbance were measured using the XTT assay kit (Roche, Cat. No. 11465015001) according to the manufacturer's instructions as described previously [22]. The XTT formazan complex was quantitatively measured at $492 \mathrm{~nm}$ using an ELISA reader (Bio-Rad Laboratories, Inc.).

\section{Flow cytometry}

Human breast cancer cells $\left(1 \times 10^{6}\right.$ cells $)$ were seeded in a $100-\mathrm{mm}$ plate and cultured overnight before treatment. Then, the cells were treated with control or $10 \mu \mathrm{M}$ of indicated drugs for $48 \mathrm{~h}$. Then treated cells were detected by Annexin V-FITC Apoptosis Detection Kit (Strong Biotech Corporation, Cat No.: AVK250) and Mitoscreen JC-1 kit (Mitochondrial Membrane Potential Assay, BD Biosciences: 551302) according to the manufacturer's instructions. In brief, at the end of the incubation period, the medium was removed. The treated cells were collected after washing by cold PBS. The supernatant was removed by centrifugation and then resuspended in indicated buffer by staining at room temperature in the dark for $15 \mathrm{~min}$. The stained cells were analyzed by the flow cytometer BD FACSCanto (Becton Dickinson). Apoptosis of different developmental stages 
were studied by gating the respective population in the Dot Plots.

\section{Quantitative real time PCR}

Quantitative Real time PCR were performed as described previously $[23,24]$. Total RNA was extracted from the breast cancer cells using the illustra ${ }^{\text {tm }}$ RNAspin Mini RNA Isolation Kit (GE Healthcare, Cat. No. 25-0500) and according to the manufacturer's instructions. Reverse transcription was performed using the Superscript first strand synthesis kit (Invitrogen, Number: 11904018). Quantitative real-time PCR analyses using the comparative CT method were performed on an ABI PRISM 7700 Sequence Detector System using the SYBR Green PCR Master Mix kit (Perkin Elmer, Applied Biosystems, Wellesley, MA, USA) according to the manufacturer's instructions. Following initial incubation at $50{ }^{\circ} \mathrm{C}$ for $2 \mathrm{~min}$ and $10 \mathrm{~min}$ at $95{ }^{\circ} \mathrm{C}$, amplification was performed for 40 cycles at $95{ }^{\circ} \mathrm{C}$ for $20 \mathrm{~s}, 65{ }^{\circ} \mathrm{C}$ for $20 \mathrm{~s}$ and $72{ }^{\circ} \mathrm{C}$ for $30 \mathrm{~s}$. Primers used were: $\operatorname{Skp} 2$ forward, $5^{\prime}$ TTA GTC GGG AGA ACT TTC CAG GTG-3' and Skp2 reverse, 5'-AGT CAC GTC TGG GTG CAG ATTT-3'. RhoA forward, 5'-GAG CAC ACA AGG CGG GAG-3' and RhoA reverse, 5'-CTT GCA GAG CAG CTC TCG TAG-3'. GAPDH forward, 5'-TGC ACC ACC AAC TGC TTAGC-3' and GAPDH reverse, 5'-GGC ATG GAC TGT GGT CATGA-3'. GAPDH was used as the housekeeping gene for data normalization. For microRNA, qPCR assay was performed in accordance with the previous study [25].

Total miRNA was extracted from breast cancer cells using the mirVana ${ }^{\mathrm{Tm}}$ miRNA Isolation Kit (Life Technologies Corporation, Cat. No. AM1560) according to the manufacturer's instructions. Reverse transcription was performed using TaqMan microRNA Reverse transcription kit (Life Technologies Corporation, Number: 4366596). Quantitative real-time PCR analyses using the comparative CT method were performed on an $\mathrm{ABI}$ PRISM 7700 Sequence Detector System using the SYBR Green PCR Master Mix kit (Perkin Elmer, Applied Biosystems, Wellesley, MA, USA) according to the manufacturer's instructions. Following initial incubation at $50{ }^{\circ} \mathrm{C}$ for $2 \mathrm{~min}$ and $10 \mathrm{~min}$ at $95{ }^{\circ} \mathrm{C}$, amplification was performed for 40 cycles at $95{ }^{\circ} \mathrm{C}$ for $20 \mathrm{~s}, 65{ }^{\circ} \mathrm{C}$ for $20 \mathrm{~s}$ and $72{ }^{\circ} \mathrm{C}$ for $30 \mathrm{~s}$. Primers used were: miR-16 forward, 5' - CGC GCT AGC AGC ACG TAA AT-3' and miR-16 reverse, $5^{\prime}$ - GTG CAG GGT CCG AGG T-3'. miR-215p forward, $5^{\prime}$ - GCC CGC TAG CTT ATC AGA CTG ATG-3' and miR-21-5p reverse, 5'- GTG CAG GGT CCG AGG T-3'. miR-26-5p forward, 5' - CGC CGC TTC AAG TAA TTC AGG AT-3' and miR-26-5p reverse, 5' - GTG CAG GGT CCG AGG T-3'. miR-30-5p forward, 5' - GCG TGT AAA CAT CCT CGA CTG G$3^{\prime}$ and miR-30-5p reverse, 5'- GCA GGG ACC GTG
GT-3'. miR-16 was used as the housekeeping gene for data normalization.

\section{Western blot analysis}

Western blot analyses were performed as described previously [26, 27]. Cellular extracts of the human breast cancer cell line treated with DMSO or indicated compounds for $24 \mathrm{~h}$ were prepared according to the manufacturer's instructions. The equal amounts of protein were fractionated on a 6 or 12\% SDS-PAGE and transferred to polyvinylidene difluoride (PVDF) membranes. The membranes were then blocked with $5 \%$ nonfat dried milk for $30 \mathrm{~min}$ and incubated in primary antibody for $3 \mathrm{~h}$ in room temperature. The primary antibodies used were: anti-PARP antibody (Cell Signaling, ratio: 1:1000), anti-Skp2 antibody (Cell Signaling, ratio: 1:1000), anti- $\beta$ actin antibody (Santa Cruz, IB: 1:10000). The primary antibody and secondary antibody were diluted with $1 \%$ nonfat dried milk in 1X TBST (Tris-Buffered Saline Tween-20). Blots were washed by 1X TBST and incubated in horseradish peroxidase-conjugated secondary anti-mouse or anti-rabbit antibodies (Santa Cruz, ratio: 1:5000) for one hour in room temperature. After washing by $1 \mathrm{X}$ TBST again, protein signal was detected by chemiluminescence, using the Super Signal substrate (Pierce, Number: 34087).

\section{High-performance liquid chromatography (HPLC) conditions}

HPLC analysis was performed in an Agilent 1100 HPLC system using a column (Nova-Pak ${ }^{\circ}$ C18, $4 \mu \mathrm{m}, 3.9 \times$ $150 \mathrm{~mm})$. The two solvents, trifluoroacetic acid $(0.05 \%)$ and $\mathrm{CH}_{3} \mathrm{CN}$ were the A and B solvents, respectively, for the mobile phase. Gradient elution was programmed as follows: $\quad(\mathrm{A}) /(\mathrm{B})=95 / 5 \quad(0 \quad \mathrm{~min}) \rightarrow(\mathrm{A}) /(\mathrm{B})=0 / 100$ (40 min). Chromatograms were recorded at a flow of 0 . $6 \mathrm{ml} / \mathrm{min}$ and at a wavelength of $254 \mathrm{~nm}$ with the column maintained at $25{ }^{\circ} \mathrm{C}$.

\section{miRNA target prediction}

The analysis of miRNA predicted targets was determined using the algorithm TargetScan (http://www.targetscan.org/vert_71/) [28].

\section{Statistical analyses for cell line studies}

All values were the means \pm standard error of mean (SEM) of the replicate samples ( $n=3$ to 6 , depending on the experiment) and experiments were repeated a minimum of three times. Differences between two groups were assessed using the unpaired two-tailed Student's $t$ test or by ANOVA if more than two groups were analyzed. The Tukey test was used as a post-hoc test in ANOVA for testing the significance of pairwise group comparisons. $P$-values $<0.05$ were considered statistically 
significant in all comparisons. SAS9.4 was used for all calculations.

\section{Results}

The composition of AC

$\mathrm{AC}$ is a mushroom that is traditionally used for health reasons in Taiwan. Triterpenoids isolated from AC, including antcin $\mathrm{K}$, antcin $\mathrm{B}$, eburicoic acid, and dehydroeburicoic acid, exhibit antitumor effects [29-34]. We assessed the composition of AC through highperformance liquid chromatography (HPLC) analysis. Our HPLC result demonstrated that AC contained antcin $\mathrm{K}$, antcin $\mathrm{C}$, antcin $\mathrm{B}$, methyl antcinate $\mathrm{B}$, eburicoic acid, and dehydroeburicoic acid (Fig. 1). These data suggest that AC may achieve potential antitumor abilities due to these compounds.

\section{Effect of $A C$ on the proliferation of different breast cancer} cell lines

To study the effects of AC on human ER-positive breast cancer cells, MCF-7 cells and acquired tamoxifen-resistant MCF-7 cells were used as a tumor cell model. First, we tested the effects of various doses of $\mathrm{AC}$ on the proliferation of the two breast cancer cell lines through the XTT assay. Our result revealed that $\mathrm{AC}$ significantly inhibited the growth of MCF-7 cells in a time- and dose-dependent manner (IC50: $185.043 \mu \mathrm{g} / \mathrm{mL}$ in $48 \mathrm{~h}$ ) (Fig. 2a). Moreover, AC inhibited the proliferation of tamoxifen-resistant MCF-7 cells in a dose-dependent and time-dependent manner (IC50: $195.97 \mu \mathrm{g} / \mathrm{mL}$ in $48 \mathrm{~h}$ ) (Fig. 2b). Next, we investigated that effect of combine therapy with $\mathrm{AC}$ and tamoxifen on the tamoxifen-resistant breast cancer cells. In Fig. $2 \mathrm{~b}, 10^{-6} \mathrm{M}$ tamoxifen can not inhibit the proliferation of tamoxifen-resistant MCF-7 cells. However, combination treatment with $\mathrm{AC}$ and $10^{-6} \mathrm{M}$ tamoxifen can inhibit the proliferation of tamoxifen-resistant MCF-7 cells in a dose-dependent and time-dependent manner, even better than $\mathrm{AC}$ only did (Fig. 2b).

These data suggested that AC exhibits a potent growth inhibitory activity in human ER-positive breast cancer cells, including those resistant to tamoxifen. Combine therapy with tamoxifen have the better inhibitory effect on the proliferation of tamoxifen-resistant MCF-7 cells than only AC did.

\section{Effects of AC on the apoptosis of breast cancer cells in vitro}

To further investigate whether the inhibition of cell proliferation induced by $\mathrm{AC}$ was associated with apoptosis, we determined the mechanism of $\mathrm{AC}$ in the two breast cancer cells. The cells were treated with the indicated compounds for $24 \mathrm{~h}$, and then cell apoptosis was analyzed through

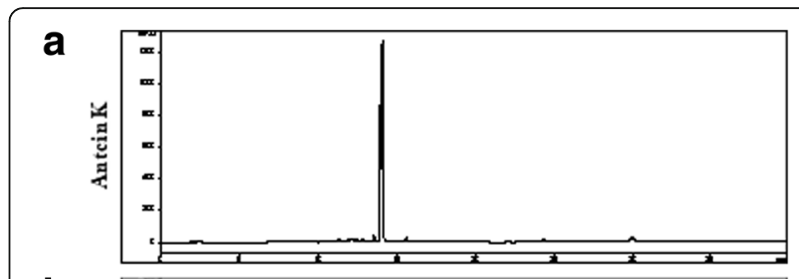

b

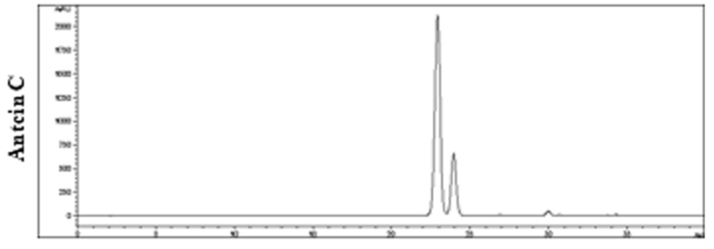

C
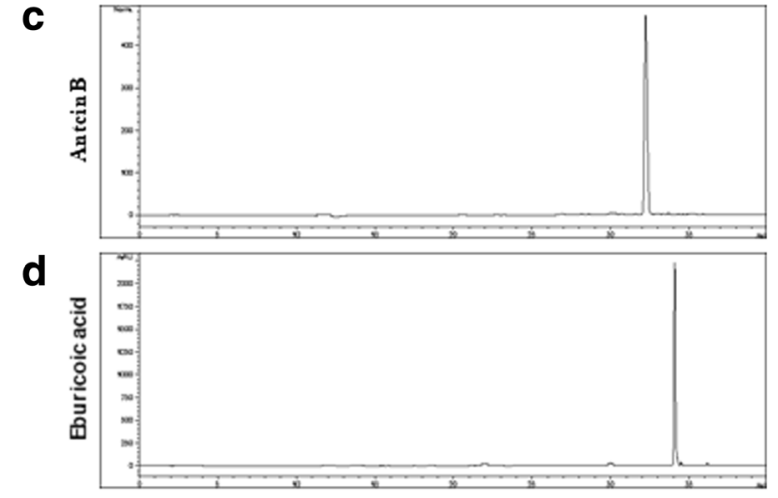

e
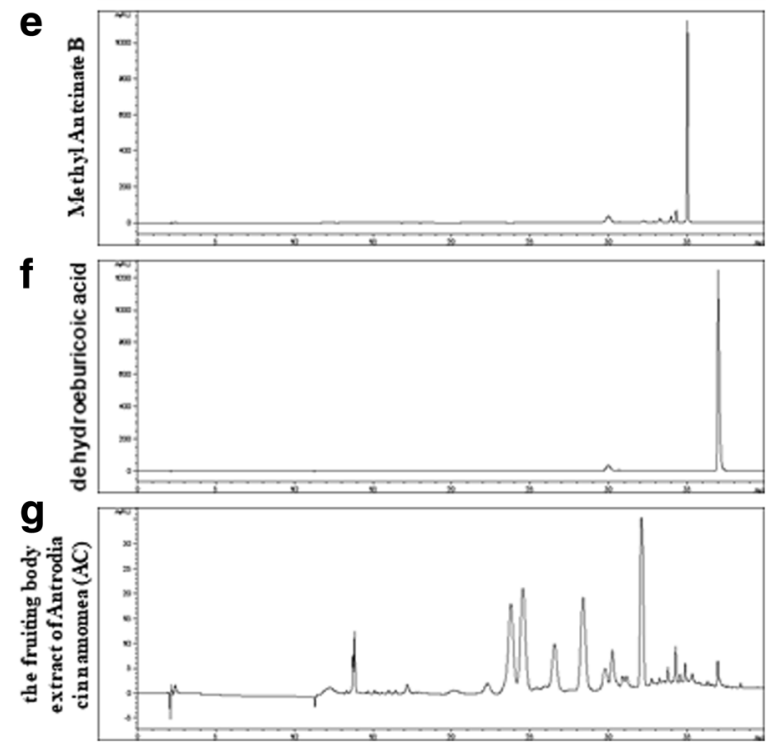

Fig. 1 HPLC chromatograms of antcin K (a), antcin C (b), antcin B (c), eburicoic acid (d), methyl antcinate B (e), dehydroeburicoic acid (f) and the extract of Antrodia cinnamomea (AC) (g)

flow cytometry with annexin V/PI dual staining. The results demonstrated that AC significantly induced apoptosis in the two breast cancer cells in a dose-dependent manner (Fig. 3a). Tetraethyl benzimidazolyl carbocyanine iodide (JC-1), a cationic dye, can accumulate in energized mitochondria. JC-1 exists in two different states, including aggregates (at high concentrations) or monomers (at low 


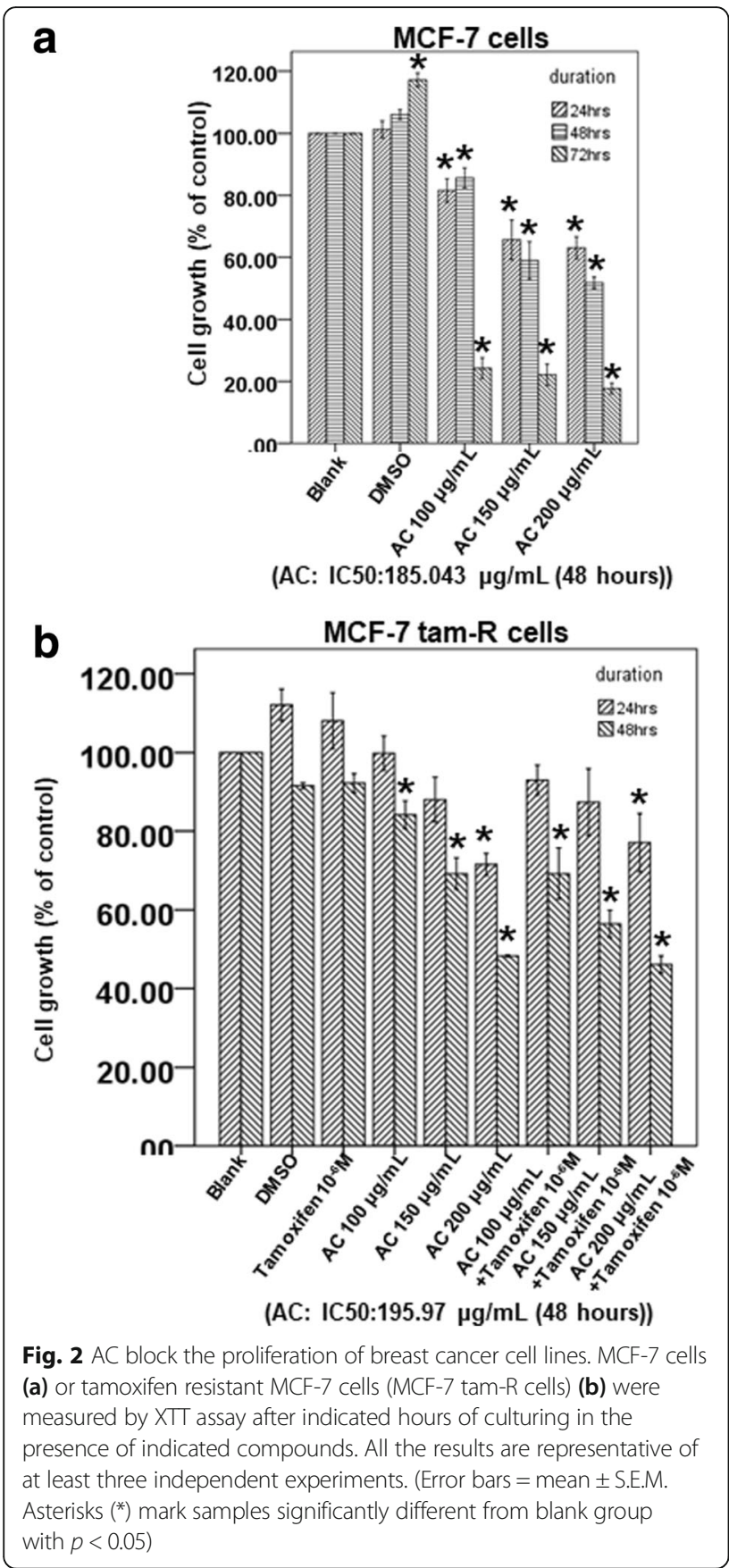

dye concentrations), each with the different emission spectra. At low concentrations from low mitochondrial membrane potential, JC-1 yields green fluorescence with emission of $530 \pm 15 \mathrm{~nm}$. At high concentrations from high mitochondrial membrane potential, JC-1 yields a red to orange colored emission of $590 \pm 17.5 \mathrm{~nm}$. A decrease in the aggregate fluorescent count is indicative of depolarization whereas an increase is indicative of hyperpolarization. By using the mitochondrial membrane potential assay (mitoscreen JC-1 staining assay), we also confirmed that the 2 breast cancer cells treated with AC underwent apoptosis through mitochondrial depolarization (Fig. 3b). These results suggested that apoptosis is the mechanism of cell death induced by $\mathrm{AC}$ in ER-positive and tamoxifen-resistant breast cancer cells.

\section{AC reduces the protein expression and mRNA level of skp2}

In a previous study, skp2 (S-phase kinase-associated protein 2) was significantly overexpressed in breast cancer samples and cell lines, and a high skp2 expression positively correlated with poor prognosis of breast cancer [35]. The Ras homolog gene family, member A (RhoA) GTPase is crucial for cancer metastasis, and RhoA transcription is regulated by the Skp2 complex [36]. To determine the mechanism by which $\mathrm{AC}$ regulates the proliferation of breast cancer cells, we also determined the mRNA and protein expression of skp2 in the 2 breast cancer cells treated with AC. Our results revealed that AC inhibited the mRNA expression of skp2 in MCF-7 and acquired tamoxifen-resistant MCF-7 cells (Fig. 4a and b). We also determined the mRNA expression of RhoA through qPCR. AC inhibited the mRNA expression of RhoA in both the breast cancer cells (Fig. $4 \mathrm{c}$ and $\mathrm{d}$ ). We also found that AC inhibited the protein expression of skp2 in MCF-7 and tamoxifen-resistant MCF-7 cells. In addition, AC induced the protein expression of cleaved poly (ADP-ribose) polymerase (PARP) in both the breast cancer cell lines (Fig. 4e and f). Our data suggested that $\mathrm{AC}$ inhibits growth in both ER-positive and tamoxifen-resistant breast cancer cells by modulating apoptosis and the protein and mRNA expressions of skp2.

\section{Effect of AC on microRNAs for regulating skp2}

In previous studies, microRNAs have been reported to inhibit cancer cell proliferation and induce apoptosis by targeting the skp2 pathway $[37,38]$. In Fig. 4e and f, we found the protein expression of Skp2 decreased in both ER-positive and tamoxifen-resistant breast cancer cells under AC treatment. Furthermore, qPCR showed that the mRNA expression of $S k p 2$ and downstream genes, $R h o A$, was inhibited by treatment of both ER-positive and tamoxifen-resistant breast cancer cells with AC (Fig. 4a-d). MicroRNA may be involved in the mechanism of AC involving the skp2 signaling pathway.

To investigate this hypothesis, a TargetScan analysis (http://www.targetscan.org/vert_71/) was applied to identify putative microRNA targets for Skp2 [28]. The TargetScan analysis revealed 3 potential microRNAs for targeting Skp2, namely miR-21-5p, miR-26-5p, and miR30-5p (Fig. 5a). To validate this result, we determined the microRNA expression through qPCR analysis in different breast cells treated with dimethyl sulfoxide or 


\section{a}

24 hours

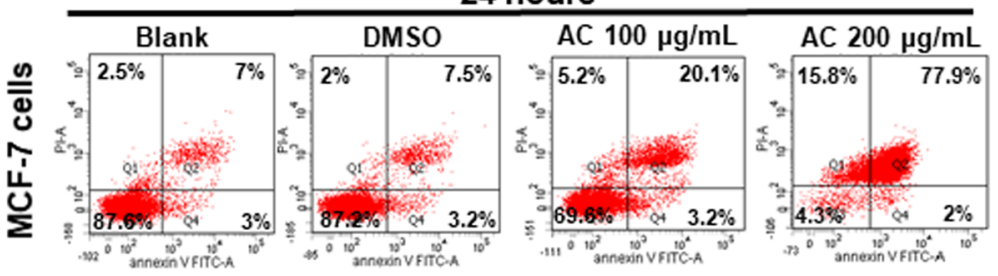

24 hours

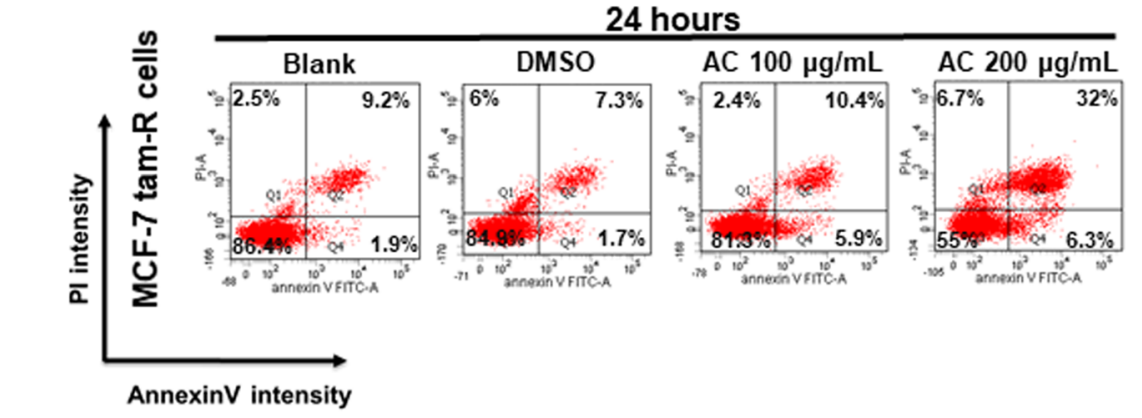

b

24 hours
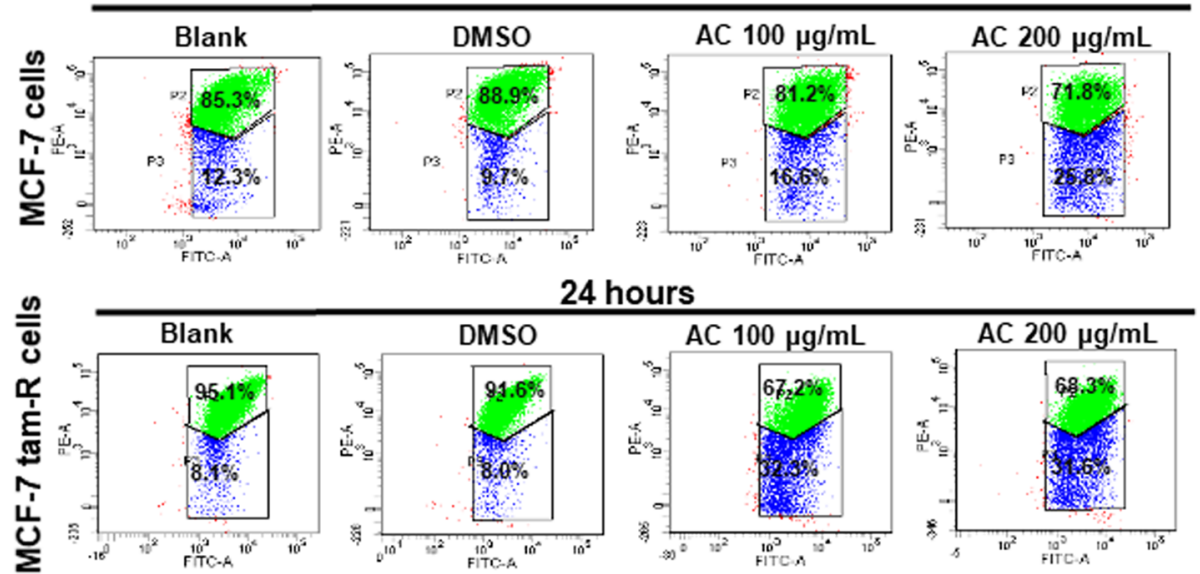

Fig. $3 \mathrm{AC}$ induces apoptosis in breast cancer cells. Breast cancer cells were treated without or with indicated compounds for $24 \mathrm{~h}$. Cell apoptosis was detected by flow cytometry with annexin-V-FITC/PI dual staining or mitochondrial membrane potential assay (mitoscreen JC-1 staining assay). a For annexin-V-FITC/PI dual staining, the representative histograms of flow cytometric analysis using double staining with annexin-V-FITC (FITC-A) and PI (PI-A). Q1 (annexin-V-/PI+) show necrosis cells; Q2 (annexin-V+/PI+) show the late apoptosis cells; Q3 (annexin-V-/PI-) show normal cells; Q4 (annexin-V+/PI-) show the early apoptosis cells. b For mitochondrial membrane potential assay (mitoscreen JC-1 staining assay), dot Plots revealing depolarization of mitochondria in treated HCT 116 cells. The percentage of events in the upper gate (P2) and lower gate (P3) represent population of treated breast cancer cells having normal and depolarized mitochondria respectively

AC. Our results revealed that AC increased the microRNA expression of miR-21-5p, miR-26-5p, and miR-30-5p in MCF-7 and tamoxifen-resistant MCF-7 cells (Fig. 5b and c). Our data suggested that AC suppressed the mRNA expression of Skp2 by increasing the expression of miR-21-5p, miR-26-5p, and miR-30$5 \mathrm{p}$ in both ER-positive and tamoxifen-resistant cells.

\section{Discussion}

MCF-7 is a stable tumor cell line derived from a patient with metastatic breast cancer; it contains ERs and is estrogen responsive. Moreover, it is the most widely used and best characterized cell line for investigating acquired tamoxifen resistance [39-43]. For tamoxifen-resistant MCF-7 cells, one proteome report demonstrated that tamoxifen-resistant breast cancer cells are characterized by downregulated ER signaling, the activation of alternative survival pathways, and enhanced cell motility, including RhoA protein [39]. Our result revealed that AC exhibited a higher IC50 for tamoxifen-resistant MCF-7 cells $(195.97 \mu \mathrm{g} / \mathrm{mL})$ than that for MCF-7 cells (185. $043 \mu \mathrm{g} / \mathrm{mL}$ ). Thus, tamoxifen-resistant MCF-7 cells may activate some alternative survival pathways against these compounds. Moreover, AC can inhibit the mRNA expression of RhoA, the upregulated protein in tamoxifenresistant breast cancer cells, in both the ER-positive and 

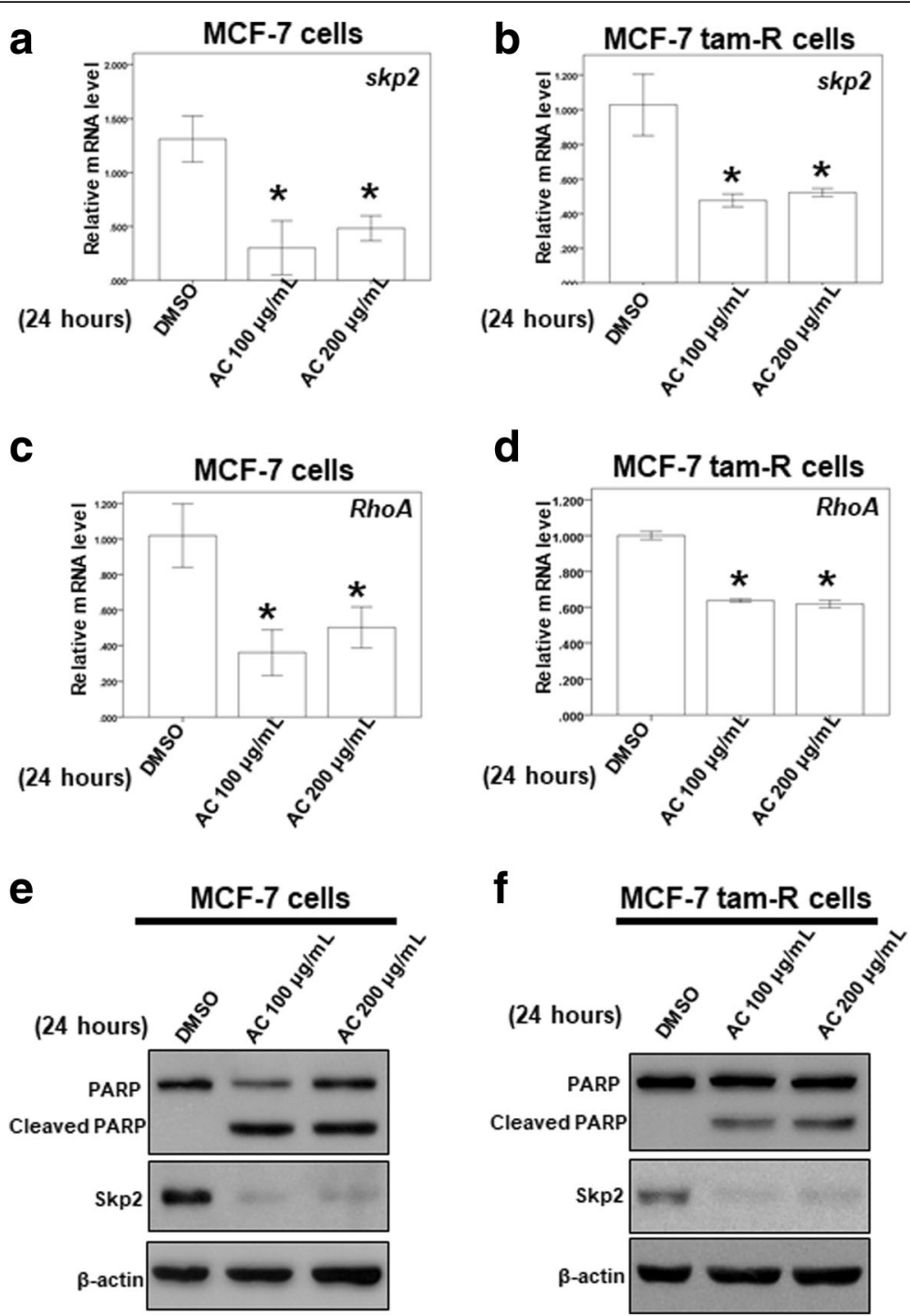

Fig. 4 The effect of $A C$ on the mRNA expression of skp2 and RhoA and the protein expression of PARP and skp2. a-d Total mRNA was extracted from the two breast cancer cells after treat without or with indicated drugs for $24 \mathrm{~h}$. The coding regions of human Skp2 and RhoA were used as probes for real time polymerase chain reaction analysis. e, f Total cell extracts of the two breast cancer cells were harvested from cells treated with DMSO or indicated concentrations of AC for $24 \mathrm{~h}$. The protein was immunoblotted with polyclonal antibodies specific for PARP or Skp2. $\beta$ actin was used as an internal loading control. (Error bars $=$ mean \pm S.E.M. Asterisks $\left(^{*}\right)$ mark samples significantly different from DMSO group with $p<0.05$ )

tamoxifen-resistant breast cancer cells (Fig. 4c and d). These results suggest that RhoA signaling may be an important pathway through which AC can inhibit the growth of both the ER-positive breast cancer cells and breast cancer cells with acquired tamoxifen resistance.

Some previous studies have demonstrated that AC extract can inhibit the growth of breast cancer cell lines $[20,21]$. Shang et al. demonstrated that AC fruiting body extracts can deregulate the PI3K/Akt/mTOR signaling pathway and induce apoptosis in T47D breast cancer cells [20]. Kumar et al. demonstrated that antrodin $\mathrm{C}$ attenuates the TGF- $\beta 1$-induced epithelial mesenchymal transition, migration, and invasion of MCF-7 cells through the suppression of $\operatorname{Smad} 2 / 3$ and $\beta$-catenin signaling pathways [21]. Su reported that ethyl acetate extracts of $\mathrm{AC}$ exhibited antiproliferation effects against MDA-MB-231 cells, a triple-negative breast cancer cell line [19]. However, the effect of $\mathrm{AC}$ on the acquired tamoxifen-resistant breast cancer remains unclear. Our results revealed that AC could inhibit both the ERpositive and acquired tamoxifen-resistant MCF-7 cells. Our data also suggested that AC could be developed as a potential candidate against acquired tamoxifenresistant breast cancer. 

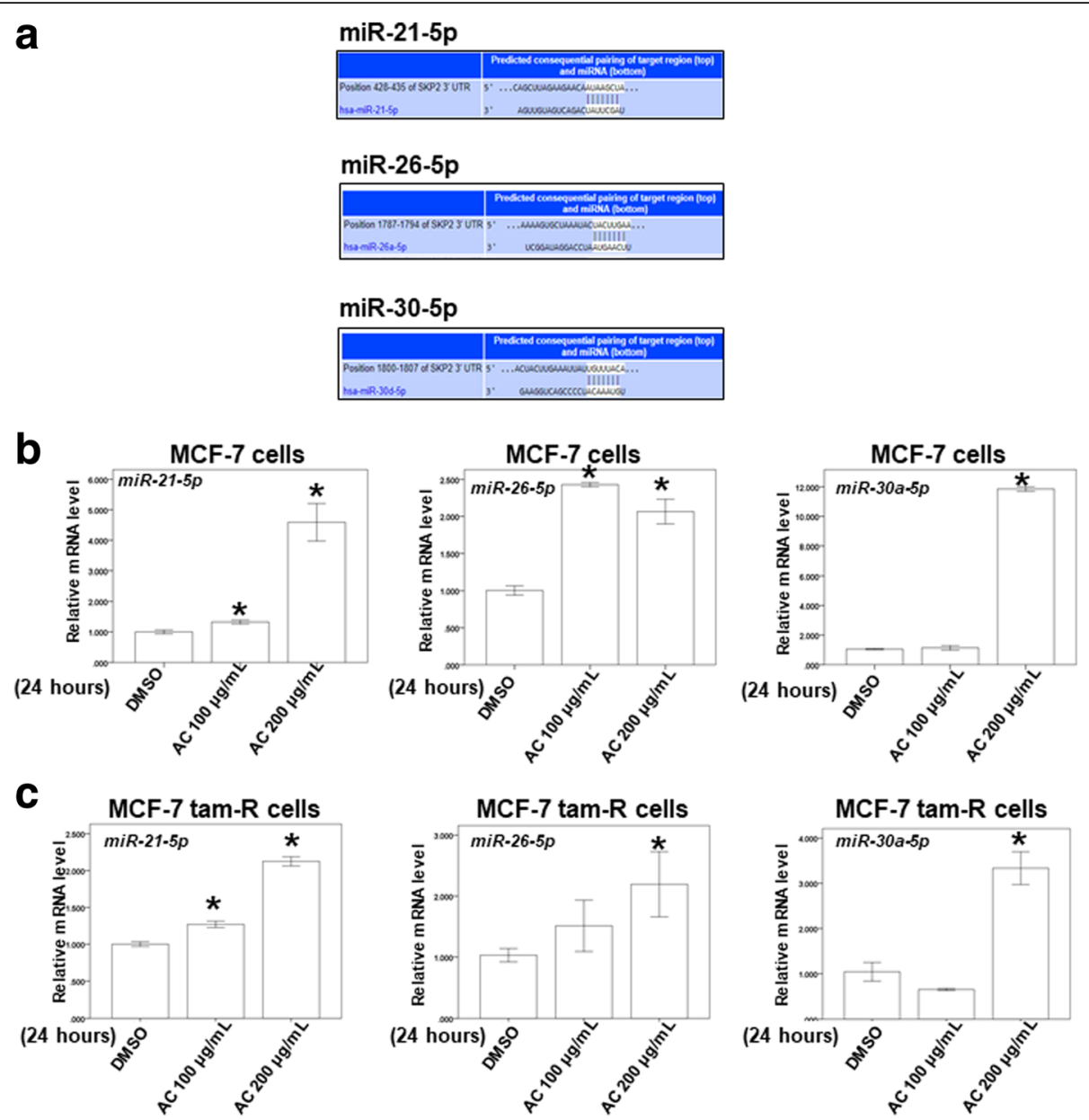

Fig. 5 The effect of AC on the microRNA expression of miR-21-5p, miR-26-5p and miR-30a-5p. a miRNA target prediction of skp2. The conserved miR-21-5p, miR-26-5p and miR-30a-5p binding sites in skp2 3'-UTR region are detected by TargetScan analysis. b-c Total microRNA was extracted from the two breast cancer cells after treat without or with indicated drugs for $24 \mathrm{~h}$. The coding regions of miR-21-5p, miR-26-5p and miR-30a-5p were used as probes for real time polymerase chain reaction analysis. (Error bars $=$ mean \pm S.E.M. Asterisks $\left(^{*}\right.$ ) mark samples significantly different from DMSO group with $p<0.05$ )

Shang et al. used tree different fruiting bodies of AC harvested at 3,6, and 9 months to investigate their cytotoxicity against T47D cells, a human mammary ductal carcinoma cell line (ER-positive). After $48 \mathrm{~h}$ of treatment, the IC50 of T47D cells was $52.7 \mu \mathrm{g} / \mathrm{mL}(3-\mathrm{mo}$ fruiting body), $122.6 \mu \mathrm{g} / \mathrm{mL}$ (6-mo fruiting body), and $141.9 \mu \mathrm{g} / \mathrm{mL}$ (9-mo fruiting body) [20]. In our study, we used the 10-month fruiting body of AC; the IC50 values of tamoxifen-resistant MCF-7 and MCF-7 cells were 195.97 and $185.043 \mu \mathrm{g} / \mathrm{mL}$, respectively. The difference between these results may be attributed to the different culture duration and different breast cancer cell lines. Our HPLC result revealed that the composites of AC included antcin $\mathrm{K}$, antcin $\mathrm{C}$, antcin $\mathrm{B}$, methyl antcinate $\mathrm{B}$, eburicoic acid, and dehydroeburicoic acid. In previous studies, antcin $\mathrm{K}$ has been shown to exhibit antitumor effects against hepatoma and leukemia [12, 29, 44]. Antcin C, antcin B, and eburicoic acid also exhibit antitumor effects against hepatoma [31, 45, 46]. Dehydroeburicoic acid exhibits antitumor effects against the breast cancer T47D cell line [20]. Thus, dehydroeburicoic acid in AC may play an important role against breast cancer. However, numerous composites in $\mathrm{AC}$ remain unidentified. These composites also play an important role in the antitumor activity against breast cancer, including ER-positive and acquired tamoxifenresistant breast cancer.

Bhatt et al. demonstrated tamoxifen can stimulate p38MAPK (p38 mitogen-activated protein kinases) to catalyze phosphorylation of Skp2 at serine-64 that drives ubiquitin-dependent proteasomal degradation of NKX31 to induce Oct-4 (octamer-binding transcription factor 4) gene expression in the presence of tamoxifen. These results suggested the crucial role of $S \mathrm{kp} 2 / \mathrm{p} 38 \mathrm{MAPK} /$ NKX3-1 mediated Oct-4 expression in driving tamoxifen resistance in MCF-7 cells [47]. Previous studies have 
demonstrated that microRNAs such as miR-186 and miR-340 can inhibit cancer cell proliferation and induce apoptosis by targeting the Skp2 pathway [37, 38]. Another previous study demonstrated that $\mathrm{AC}$ exerts an inhibitory effect on breast cancer stem cells from the MDA-MB231 cell line. AC also downregulated several microRNAs, including miR-381 and miR-711, in MDAMB231 cells, a triple-negative breast cancer cell line [19]. However, the effect of AC on the expression of microRNA and Skp2 in ER-positive breast cancer and acquired tamoxifen-resistant breast cancer remain unclear. We first demonstrated that AC suppresses the mRNA expression of skp2 by increasing the expression of miR21-5p, miR-26-5p, and miR-30-5p in MCF-7 and tamoxifen-resistant MCF-7 cells. In previous study, higher levels of miR-26a were significantly associated with clinical benefit and prolong time to progression on tamoxifen therapy of breast cancer [48]. Higher expression levels of miR-30 family (miR-30a and miR-30c) were significantly associated with benefit of tamoxifen treatment and with longer progression free survival of breast cancer patients [49]. Our data suggested AC inhibited different breast cancer cell lines through different microRNA signaling pathways. It is possible that $\mathrm{AC}$ may have clinical benefit of tamoxifen treatment in breast cancer patients. However, AC is the crude extract and contain a lot of pure compounds, many different mechanisms are involved through these different pure compounds [10, 12-18]. It is possible that Skp2 signaling pathway is not the only major pathway under the treatment of AC. In the further, we will investigate the in vivo and in vitro effect of these pure compounds on the breast cancer to clarify the clear mechanism of pure compounds with respect to tamoxifen resistance.

\section{Conclusion}

In summary, this is a novel study that demonstrated the mechanism by which AC can inhibit the proliferation of ER-positive and acquired tamoxifen-resistant breast cancer cells. The study results suggest that $\mathrm{AC}$ could be a novel anticancer agent in the armamentarium of breast cancer management. Furthermore, additional pure compounds from $\mathrm{AC}$ that might serve as promising antibreast cancer candidates should be identified for further clinical trials.

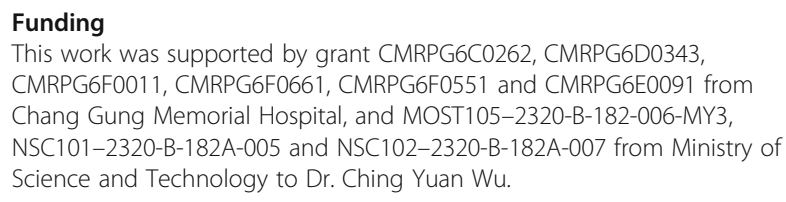

Availability of data and materials

The datasets used and analyzed during the current study available from Ching-Yuan Wu, M.D., Ph. D. on reasonable request

(smbepigwu77@gmail.com).

\section{Authors' contributions}

CYW conceived the idea and designed experiments and wrote manuscript JYC, YHY, LHS, YSL, JL, HTL and YCC performed the experiments; CLL, CNL, YYL, FCK and PCC analyzed the data; HKL, KDL, YHT revised the manuscript. All authors reviewed and approved the final version.

Ethics approval and consent to participate Not applicable.

\section{Competing interests}

The authors declare that they have no competing interests.

\section{Publisher's Note}

Springer Nature remains neutral with regard to jurisdictional claims in published maps and institutional affiliations.

\section{Author details}

'Department of Pharmacy, Chiayi Chang Gung Memorial Hospital, Chiayi, Taiwan. ${ }^{2}$ Department of Chinese Medicine, Chiayi Chang Gung Memorial Hospital, Chiayi, Taiwan. ${ }^{3}$ School of Chinese medicine, College of Medicine, Chang Gung University, Tao-Yuan, Taiwan. ${ }^{4}$ Departments of Nephrology, Chiayi Chang Gung Memorial Hospital, Chiayi, Taiwan. ${ }^{5}$ Kidney and Diabetic Complications Research Team (KDCRT), Chiayi Chang Gung Memorial Hospital, Chiayi, Taiwan. ${ }^{6}$ Department of Hematology and oncology, Chiayi Chang Gung Memorial Hospital, Chiayi, Taiwan. ${ }^{7}$ Division of Hematology and Oncology, Department of Internal Medicine, Taipei Medical University Hospital, Taipei, Taiwan. ${ }^{8}$ Institute of Molecular Biology, National Chung Cheng University, No.168, Sec. 1, University Rd., Minhsiung Chiayi County 62102, Taiwan, Republic of China. ${ }^{9}$ Division of Acupuncture and Chinese Traumatology, Department of TCM, Kaohsiung Chang Gung Memorial Hospital and Chang Gung University College of Medicine, Kaohsiung, Taiwan.

${ }^{10}$ Department of Otolaryngology, Chang Gung Memorial Hospital, Chiayi, Taiwan. ${ }^{11}$ Center of Excellence for Chang Gung Research Datalink, Chang Gung Memorial Hospital, Chiayi, Taiwan.

Received: 8 November 2017 Accepted: 16 April 2018

Published online: 09 May 2018

\section{References}

1. Ferlay J, Shin HR, Bray F, Forman D, Mathers C, Parkin DM. Estimates of worldwide burden of cancer in 2008: GLOBOCAN 2008. Int J Cancer. 2010; 127(12):2893-917.

2. Gutierrez MC, Detre S, Johnston S, Mohsin SK, Shou J, Allred DC, Schiff R, Osborne CK, Dowsett M. Molecular changes in tamoxifen-resistant breast cancer: relationship between estrogen receptor, HER-2, and p38 mitogenactivated protein kinase. J Clin Oncol. 2005;23(11):2469-76.

3. Viedma-Rodriguez R, Baiza-Gutman L, Salamanca-Gomez F, Diaz-Zaragoza M, Martinez-Hernandez G, Ruiz Esparza-Garrido R, Velazquez-Flores MA, ArenasAranda D. Mechanisms associated with resistance to tamoxifen in estrogen receptor-positive breast cancer (review). Oncol Rep. 2014;32(1):3-15.

4. Martin HL, Smith L, Tomlinson DC. Multidrug-resistant breast cancer: current perspectives. Breast Cancer. 2014;6:1-13.

5. Chen JJ, Lin WJ, Liao CH, Shieh PC. Anti-inflammatory benzenoids from Antrodia camphorata. J Nat Prod. 2007;70(6):989-92.

6. Huang CC, Hsu MC, Huang WC, Yang HR, Hou CC. Triterpenoid-rich extract from Antrodia camphorata improves physical fatigue and exercise performance in mice. Evid Based Complement Alternat Med. 2012;2012:364741.

7. Hsu YL, Kuo PL, Cho CY, Ni WC, Tzeng TF, Ng LT, Kuo YH, Lin CC. Antrodia cinnamomea fruiting bodies extract suppresses the invasive potential of human liver cancer cell line PLC/PRF/5 through inhibition of nuclear factor kappaB pathway. Food Chem Toxicol. 2007;45(7):1249-57.

8. Ker YB, Peng CC, Chang WL, Chyau CC, Peng RY. Hepatoprotective bioactivity of the glycoprotein, antrodan, isolated from Antrodia cinnamomea mycelia. PLoS One. 2014;9(4):e93191.

9. Wu MD, Cheng MJ, Wang WY, Huang HC, Yuan GF, Chen JJ, Chen IS, Wang $B C$. Antioxidant activities of extracts and metabolites isolated from the fungus Antrodia cinnamomea. Nat Prod Res. 2011;25(16):1488-96.

10. Liu JJ, Huang TS, Hsu ML, Chen CC, Lin WS, Lu FJ, Chang WH. Antitumor effects of the partially purified polysaccharides from Antrodia camphorata and the mechanism of its action. Toxicol Appl Pharmacol. 2004;201(2):186-93. 
11. Tsai MY, Hung YC, Chen YH, Chen YH, Huang YC, Kao CW, Su YL, Chiu HH, Rau KM. A preliminary randomised controlled study of short-term Antrodia cinnamomea treatment combined with chemotherapy for patients with advanced cancer. BMC Complement Altern Med. 2016;16(1):322.

12. Du YC, Wu TY, Chang FR, Lin WY, Hsu YM, Cheng FT, Lu CY, Yen MH, Tsui $Y T$, Chen $H L$, et al. Chemical profiling of the cytotoxic triterpenoidconcentrating fraction and characterization of ergostane stereo-isomer ingredients from Antrodia camphorata. J Pharm Biomed Anal. 2012;58:182-92.

13. Yeh CT, Rao YK, Yao CJ, Yeh CF, Li CH, Chuang SE, Luong JH, Lai GM, Tzeng YM. Cytotoxic triterpenes from Antrodia camphorata and their mode of action in HT-29 human colon cancer cells. Cancer Lett. 2009;285(1):73-9.

14. Cheng JJ, Yang CJ, Cheng CH, Wang YT, Huang NK, Lu MK. Characterization and functional study of Antrodia camphorata lipopolysaccharide. J Agric Food Chem. 2005;53(2):469-74.

15. Lee $\mathrm{HH}$, Huang RL, Chen CT, Chen HC, Hsu WC, Lu MK. Antrodia camphorata polysaccharides exhibit anti-hepatitis B virus effects. FEMS Microbiol Lett. 2002;209(1):63-7.

16. Peng CC, Chen KC, Peng RY, Chyau CC, Su CH, Hsieh-Li HM. Antrodia camphorata extract induces replicative senescence in superficial TCC, and inhibits the absolute migration capability in invasive bladder carcinoma cells. J Ethnopharmacol. 2007;109(1):93-103.

17. Shen YC, Wang YH, Chou YC, Chen CF, Lin LC, Chang TT, Tien JH, Chou CJ. Evaluation of the anti-inflammatory activity of zhankuic acids isolated from the fruiting bodies of Antrodia camphorata. Planta Med. 2004;70(4):310-4.

18. Huang HC, Liaw CC, Yang HL, Hseu YC, Kuo HT, Tsai YC, Chien SC, Amagaya S, Chen YC, Kuo YH. Lanostane triterpenoids and sterols from Antrodia camphorata. Phytochemistry. 2012;84:177-83.

19. Su YK, Shih PH, Lee WH, Bamodu OA, Wu ATH, Huang CC, Tzeng YM, Hsiao $M$, Yeh CT, Lin CM. Antrodia cinnamomea sensitizes radio-/chemo-therapy of cancer stem-like cells by modulating microRNA expression. J Ethnopharmacol. 2017;207:47-56.

20. Shang KM, Su TH, Lee WL, Hsiao WW, Chiou CY, Ho BY, Wang SY, Shyur LF. Novel effect and the mechanistic insights of fruiting body extract of medicinal fungus Antrodia cinnamomea against T47D breast cancer. Phytomedicine. 2017;24:39-48.

21. Kumar KJ, Vani MG, Chueh PJ, Mau JL, Wang SY. Antrodin C inhibits epithelial-to-mesenchymal transition and metastasis of breast cancer cells via suppression of Smad2/3 and beta-catenin signaling pathways. PLoS One. 2015;10(2):e0117111.

22. Wu CY, Hsieh CY, Huang KE, Chang C, Kang HY. Cryptotanshinone downregulates androgen receptor signaling by modulating lysine-specific demethylase 1 function. Int J Cancer. 2012:131(6):1423-34.

23. Lin YY, Lee IY, Huang WS, Lin YS, Kuan FC, Shu LH, Cheng YC, Yang YH, Wu CY. Danshen improves survival of patients with colon cancer and dihydroisotanshinone I inhibit the proliferation of colon cancer cells via apoptosis and skp2 signaling pathway. J Ethnopharmacol. 2017;209:305-16.

24. Lee $I Y$, Lin $Y Y$, Yang YH, Lin YS, Lin CL, Lin WY, Cheng YC, Shu LH, Wu CY. Dihydroisotanshinone I combined with radiation inhibits the migration ability of prostate cancer cells through DNA damage and CCL2 pathway. BMC Pharmacol Toxicol. 2018;19(1):5.

25. Chen C, Ridzon DA, Broomer AJ, Zhou Z, Lee DH, Nguyen JT, Barbisin M, Xu NL, Mahuvakar VR, Andersen MR, et al. Real-time quantification of microRNAs by stem-loop RT-PCR. Nucleic Acids Res. 2005;33(20):e179.

26. Wu CY, Cherng JY, Yang YH, Lin CL, Kuan FC, Lin YY, Lin YS, Shu LH, Cheng YC, Liu HT, et al. Danshen improves survival of patients with advanced lung cancer and targeting the relationship between macrophages and lung cancer cells. Oncotarget. 2017;8(53):90925-47.

27. Wu CY, Yang YH, Lin YY, Kuan FC, Lin YS, Lin WY, Tsai MY, Yang JJ, Cheng $Y C$, Shu LH, et al. Anti-cancer effect of danshen and dihydroisotanshinone I on prostate cancer: targeting the crosstalk between macrophages and cancer cells via inhibition of the STAT3/ CCL2 signaling pathway. Oncotarget. 2017;8(25):40246-63.

28. Agarwal V, Bell GW, Nam JW, Bartel DP. Predicting effective microRNA target sites in mammalian mRNAs. elife. 2015;4

29. Huang YL, Chu YL, Ho CT, Chung JG, Lai Cl, Su YC, Kuo YH, Sheen LY. Antcin $\mathrm{K}$, an active triterpenoid from the fruiting bodies of basswoodcultivated Antrodia cinnamomea, inhibits metastasis via suppression of integrin-mediated adhesion, migration, and invasion in human hepatoma cells. J Agric Food Chem. 2015;63(18):4561-9.

30. Du YC, Chang FR, Wu TY, Hsu YM, El-Shazly M, Chen CF, Sung PJ, Lin $Y Y$, Lin YH, Wu YC, et al. Antileukemia component, dehydroeburicoic acid from Antrodia camphorata induces DNA damage and apoptosis in vitro and in vivo models. Phytomedicine. 2012;19(8-9):788-96.

31. Hsieh YC, Rao YK, Whang-Peng J, Huang CY, Shyue SK, Hsu SL, Tzeng YM. Antcin B and its ester derivative from Antrodia camphorata induce apoptosis in hepatocellular carcinoma cells involves enhancing oxidative stress coincident with activation of intrinsic and extrinsic apoptotic pathway. J Agric Food Chem. 2011;59(20):10943-54.

32. Lee $\mathrm{Cl}$, Wu CC, Hsieh SL, Lee CL, Chang YP, Chang CC, Wang YZ, Wang JJ. Anticancer effects on human pancreatic cancer cells of triterpenoids, polysaccharides and 1,3-beta-d-glucan derived from the fruiting body of Antrodia camphorata. Food Funct. 2014;5(12):3224-32.

33. Lee YP, Tsai WC, Ko CJ, Rao YK, Yang CR, Chen DR, Yang MH, Yang CC, Tzeng YM. Anticancer effects of eleven triterpenoids derived from Antrodia camphorata. Anticancer Res. 2012;32(7):2727-34

34. Liu FS, Yang PY, Hu DN, Huang YW, Chen MJ. Antrodia camphorata induces apoptosis and enhances the cytotoxic effect of paclitaxel in human ovarian cancer cells. Int J Gynecol Cancer. 2011;21(7):1172-9.

35. Zhang W, Cao L, Sun Z, Xu J, Tang L, Chen W, Luo J, Yang F, Wang Y, Guan $X$. Skp2 is over-expressed in breast cancer and promotes breast cancer cell proliferation. Cell Cycle. 2016;15(10):1344-51.

36. Chan CH, Lee SW, Li CF, Wang J, Yang WL, Wu CY, Wu J, Nakayama Kl, Kang HY, Huang HY, et al. Deciphering the transcriptional complex critical for RhoA gene expression and cancer metastasis. Nat Cell Biol. 2010;12(5):457-67.

37. He W, Feng J, Zhang Y, Wang Y, Zang W, Zhao G. microRNA-186 inhibits cell proliferation and induces apoptosis in human esophageal squamous cell carcinoma by targeting SKP2. Lab Investig. 2016;96(3):317-24.

38. Fernandez S, Risolino M, Mandia N, Talotta F, Soini Y, Incoronato M Condorelli G, Banfi S, Verde P. miR-340 inhibits tumor cell proliferation and induces apoptosis by targeting multiple negative regulators of p27 in nonsmall cell lung cancer. Oncogene. 2015;34(25):3240-50

39. Zhou C, Zhong Q, Rhodes LV, Townley I, Bratton MR, Zhang Q, Martin EC, Elliott $\mathrm{S}$, Collins-Burow BM, Burow ME, et al. Proteomic analysis of acquired tamoxifen resistance in MCF-7 cells reveals expression signatures associated with enhanced migration. Breast Cancer Res. 2012;14(2):R45.

40. Fan P, Yue W, Wang JP, Aiyar S, Li Y, Kim TH, Santen RJ. Mechanisms of resistance to structurally diverse antiestrogens differ under premenopausal and postmenopausal conditions: evidence from in vitro breast cancer cell models. Endocrinology. 2009;150(5):2036-45.

41. Knowlden JM, Hutcheson IR, Jones HE, Madden T, Gee JM, Harper ME, Barrow D, Wakeling AE, Nicholson RI. Elevated levels of epidermal growth factor receptor/c-erbB2 heterodimers mediate an autocrine growth regulatory pathway in tamoxifen-resistant MCF-7 cells. Endocrinology. 2003; 144(3):1032-44.

42. Leung EY, Kim JE, Askarian-Amiri M, Joseph WR, McKeage MJ, Baguley BC. Hormone resistance in two MCF-7 breast Cancer cell lines is associated with reduced mTOR signaling, decreased glycolysis, and increased sensitivity to cytotoxic drugs. Front Oncol. 2014;4:221.

43. Nawata $\mathrm{H}$, Bronzert D, Lippman ME. Isolation and characterization of a tamoxifen-resistant cell line derived from MCF-7 human breast cancer cells. J Biol Chem. 1981;256(10):5016-21.

44. Lai $\mathrm{Cl}$, Chu YL, Ho CT, Su YC, Kuo YH, Sheen LY. Antcin K, an active triterpenoid from the fruiting bodies of basswood cultivated Antrodia cinnamomea, induces mitochondria and endoplasmic reticulum stressmediated apoptosis in human hepatoma cells. J Tradit Complement Med. 2016;6(1):48-56

45. Gokila Vani M, Kumar KJ, Liao JW, Chien SC, Mau JL, Chiang SS, Lin CC, Kuo YH, Wang SY. Antcin C from Antrodia cinnamomea protects liver cells against free radical-induced oxidative stress and apoptosis in vitro and in vivo through Nrf2-dependent mechanism. Evid Based Complement Alternat Med. 2013;2013:296082.

46. Su YC, Liu CT, Chu YL, Raghu R, Kuo YH, Sheen LY. Eburicoic acid, an active triterpenoid from the fruiting bodies of basswood cultivated Antrodia cinnamomea, induces ER stress-mediated autophagy in human hepatoma cells. J Tradit Complement Med. 2012;2(4):312-22.

47. Bhatt S, Stender JD, Joshi S, Wu G, Katzenellenbogen BS. OCT-4: a novel estrogen receptor-alpha collaborator that promotes tamoxifen resistance in breast cancer cells. Oncogene. 2016;35(44):5722-34.

48. Jansen MP, Reijm EA, Sieuwerts AM, Ruigrok-Ritstier K, Look MP, RodriguezGonzalez FG, Heine AA, Martens JW, Sleijfer S, Foekens JA, et al. High miR26a and low CDC2 levels associate with decreased EZH2 expression and 
with favorable outcome on tamoxifen in metastatic breast cancer. Breast Cancer Res Treat. 2012;133(3):937-47.

49. Rodriguez-Gonzalez FG, Sieuwerts AM, Smid M, Look MP, Meijer-van Gelder ME, de Weerd V, Sleijfer S, Martens JW, Foekens JA. MicroRNA-30c

expression level is an independent predictor of clinical benefit of endocrine therapy in advanced estrogen receptor positive breast cancer. Breast Cancer Res Treat. 2011;127(1):43-51.

Ready to submit your research? Choose BMC and benefit from:

- fast, convenient online submission

- thorough peer review by experienced researchers in your field

- rapid publication on acceptance

- support for research data, including large and complex data types

- gold Open Access which fosters wider collaboration and increased citations

- maximum visibility for your research: over $100 \mathrm{M}$ website views per year 